\title{
Determination of Shearing Properties for Tubular Pinewood under Torsion
}

\author{
Ezgi Günay*, Emre Uludogan \\ Mechanical Engineering Department, Engineering Faculty, Gazi University, Ankara, Turkey \\ Email: ${ }^{*}$ ezgigunay@gazi.edu.tr
}

Received 19 November 2014; revised 2 December 2014; accepted 18 December 2014

Copyright (C) 2015 by authors and Scientific Research Publishing Inc.

This work is licensed under the Creative Commons Attribution International License (CC BY). http://creativecommons.org/licenses/by/4.0/

(c) (i) Open Access

\section{Abstract}

In this study, tubular pinewood (Pinus sylvestris L.) specimens are tested and shear strain measurements are performed by applying torsion in $z$ direction in the consideration of light weight aircraft engineering. The objective of this paper is to contribute and generate the nonlinear material model in terms of shear modulus presented with power functions under the consideration of nonlinear behavior of wood under torque. Strain gauge measurements are performed for the maximum shear stresses which develop on the tubular specimen, along the radial $r\left(r_{\text {in }}, r_{\text {out }}\right)$, circumferential $\phi\left(\phi_{\mathrm{n}}, \phi_{\mathrm{out}}\right)$ and $\mathrm{z}$ directions, in a point-wise manner. The data is gathered and examined for the determination of the local variations of empirical shear modulus functions on transversely isotropic surfaces of the specimens. The coordinate dependent shear modulus functions of $G_{z \phi}(r), G_{z \phi}(\phi), G_{z \phi}(z)$ are derived for $G_{z \phi}(r, \phi, z)$ as the function of $r, \phi$ and $z$, respectively, by analyzing the gathered data. It is proposed to represent the shear modulus functions, $G_{z \phi}(\phi)$ and $G_{z \phi}(z)$ with the parabolic polynomials, and, to represent the shear modulus function $G_{z \phi}(r)$ with a linear equation.

\section{Keywords}

Wood Material, Shear Modulus, Transversely Isotropic, Nonlinear Material, Light Material

\section{Introduction}

Wood is modeled as a fiber composite material of transversely isotropic type. The elastic material constants of fiber composites vary along fiber directions. It is known that; the wood material behaves like a nonlinearly elas-

*Corresponding author. 
tic composite structure under torsion loading. However, in addition to this phenomenon, it also exhibits viscoelastic properties. Transversely isotropic structure of wood is related to the natural growth of a tree. Annual rings of the wood form fairly regular concentric circles in nature, giving the wood cylindrically symmetric structure. Wood material enters the lightweight materials group with its composite structure. Therefore, the use of wood materials will take place between other light composite materials considered in aircraft engineering.

Coordinate dependent material elastic constants which were represented with mathematical equations, were studied analytically by scientists [1]-[4]. An extensive body of experimental data according to the variation of in-plane shear modulus $G(\phi)$, and the variation of Young's modulus $E(\phi)$ of plywood panels were gathered and analyzed, in this sense. The mathematical relations between elastic properties of fiber and matrix structure and the wood polymer elastic constants in micromechanical level were studied [5]. In the literature we have found out that, the simulation of wood nonlinearity was formulated as equivalent stresses and equivalent plastic strain relationships by using power functions [6]-[9].

Fundamental works on wood compression were represented as continuous functions [10] [11]. Beside these, these researchers have used bilinear or tri-linear functions for the wood nonlinear modeling [12]-[17]. Generally, 2D analyses with plane-stress or plane-strain assumption were employed by most FE models for wood or wood composites and they were generally unable to completely describe the 3D stress fields.

Few attempts were found in the literature concerning with the 3D analysis of wood and associated constitutive models. In the literature survey, we haven't found an accepted nonlinear constitutive model for wood that describes the change of elastic constants in 3D as the stiffness becomes nonlinear [7] [16].

It is noteworthy that, "Japanese Iosipescu Shear Testing Method" standardized for fiber-reinforced plastics (FRP) was given in the American Society for Testing Material (ASTM) D5379. In this survey, radial and/or longitudinal plane shear behavior was mentioned.

The above mentioned test method was used in measuring the shearing properties of wood type materials [18]. The nonlinear material model presents the power functions which represent the stiffness change based on initial stiffness or stiffness of previous recurrences. Interestingly, typical nonlinearity of wood was observed under the compression loading and along with the shearing directions.

According to another study, in the modeling of the lateral buckling strength of large cross-section beam-columns, the values of the shear modulii GLT and GLR should be known. Thereafter, their variation under creep can be easily defined. In the above mentioned study, power law and exponential law were adopted for creep testing on the wood-species and a linear-parabolic model was adopted for the short term behavior. Power and exponential laws have been chosen as creep functions due to their ease of handling properly in the numerical computation of the creep strain rates [19].

In the literature, it is possible to find specific studies on the simulation of wood nonlinearity under shear and compression. The objective of one of these studies was developing a "3D finite element modeling" that corresponds to the wood material behavior [20].

In the literature survey, researchers have focused on both theoretical and experimental studies that based on genetic optimization and optical metrology in order to obtain whole displacement fields of wood-based panels under bending loading. Tests were named as "Non-statically determined tests" because of the absence of unique analytical relations. In these studies, the developing complex stress fields were found as not only depending on boundary conditions, but also on constitutive equations [21].

In order to obtain the balanced modulii in torsion (GJ) of wood-based composite materials, two finite element method (FEM) Fortran approaches (in displacement and stress) were proposed under the Saint Venant assumption. In this study, finite element analysis results were compared with the experimental values which were obtained from the torsion tests on specimens [22].

The Norway spruce was analyzed numerically using the bilinear material law, and the experimental data are available in the literature. According to this study; as the rolling shear of RT plane has shown mostly nonlinearity, it is seldom observed on the LT plane. The results of analyses with modified bilinear parameters reflected good correspondence with the experimental findings. The parameters were found to be nearly equal to the Weibull statistical distributions [23].

In the another study, the test which was named as "Arcan shear test" was used to investigate orthotropic shear modulus values of softwood Norway spruce. Video extensometer method was used in measuring the strain on the critical specimen section, and the determined moduli were evaluated by means of FEM calculations. In this study it was stated that, the 3-parameter Weibull distribution was the most appropriate method for the probabil- 
istic description of the three orthotropic shear modulii of wood [24].

In another similar publication; in which the Norway spruce was investigated again by means of the Arcan shear test, the data were obtained until failure occurs in each of the three orthotropic shear planes. In this latter study, the stress-strain curves were adapted to the linear, bilinear and Voce models [25].

A new relationship to calculate the shear modulus $G_{12}$ in terms of off-axis modulus of elasticity $E_{o}$ of orthotropic specimens such as wood-based panels was proposed. The verification of shear modulus transformation rules to obtain basic engineering constants that agrees with reliable test data and the anisotropic elasticity theory was performed [26]. The shear stress versus shear strain expressions of transversely isotropic cylindrical bar under torsion, having a finite length, was described in terms of partial differential equations [27] [28]. In the current study, two coordinate systems were used to define the coordinate dependent strain variations of pinewood specimens under torque, applied in $z$ direction. The results which were obtained by performing pointwise incremental measurements, were illustrated as curves of point-wise shear stress $\tau_{z \phi}$ vs. shear strain $\gamma_{z \phi}$, along the principal directions at the gauge locations. The torque loading was applied to the specimen in the $(r-\phi)$ plane at one end, while the other end was fixed. The related data which was gathered from all these points was shown as separate curves for each test case. The purpose was to show the variations of the $G_{z \phi}(r, \phi, z)$ as functions of $(r, \phi, z)$ [29] [30]. Consequently, these curves were formulated as empirical mathematical equations. In each test case, the coordinate dependent variations of the shear modulus functions $G_{z \phi}(r), G_{z \phi}(\phi)$ and $G_{z \phi}(z)$ along the $r, \phi$ and $z$ directions, respectively, were generated on the circumferential surface of the tubular specimen.

\section{Experiment and Method}

Tubular pinewood specimens were used in this study (Figures 1(a)-(c)). The average moisture content of the material was measured and tabulated around $6 \%-7 \%$ levels. Meanwhile, the geometry of the specimens were formed by taking fillet depths equal to the radius of the outer portion of the wood shaft (see Figure 1(c)). Thus, it became possible to minimize stress concentrations around specimen headings. The torsion load in Equation (1) was applied on the transverse plane ( $r-\phi$ plane, Figure 1(b)) which had a unit normal vector $\boldsymbol{k}$ along the $z$ direction.

$$
T=T_{z} k
$$

The measured coordinate dependent point-wise shear strain data $\left(\gamma_{x \phi}\right)_{p w}$ generated by the applied torque $\boldsymbol{T}$.

All experiments were performed in room temperature by making use of uni-axial and tri-axial rosette gauges. These gauges were bonded onto the specimens at definite locations (Figure 1(a)). In order to minimize the deviations in the test results; these specimens were manufactured from a single tree trunk. The forming procedure was performed on the wood specimens in such a way that their fibers lay longitudinally parallel to the trunk. However, there were intrinsic structural differences stemming from the number and radii of annual rings in the part of the trunk from which the specimen was taken out. The experimental set-up was displayed as a schematic diagram in Figure 2. The torsion loading was applied by using TQSM-21 torsion testing machine [31]. Data was collected by employing a specialized units [32]-[34]. The set-up included torsion test machine and two different data acquisition systems. In this study, the data was simultaneously stored in terms of output voltage difference $\left(\Delta V_{o}\right)$. As a first step, the normal strain values were obtained by reading the voltage differences from the display of the unit, and as a second step, these normal strains were converted into shear strains by using Mohr's circle [35].

\section{Measurements}

In the consideration of the resultant curves $\left(\tau_{z \phi}-\gamma_{z \phi}\right)_{p w}$, different failure stresses were established at the forward and backward rotation directions. Directions of forward and backward torque loadings, $+\alpha_{\text {ref }}$ or $-\alpha_{\text {ref }}$, indicated the fiber angles [36]. Only the forward loading case was considered in the empirical formulation of this study. Results of the experimental studies were analyzed mainly in two steps. Firstly, specific locations were defined along the $r, \phi, z$ directions on the specimens and shear stress versus strain $\left(\tau_{z \phi}-\gamma_{z \phi}\right)_{p w}$ curves were obtained for each location. 


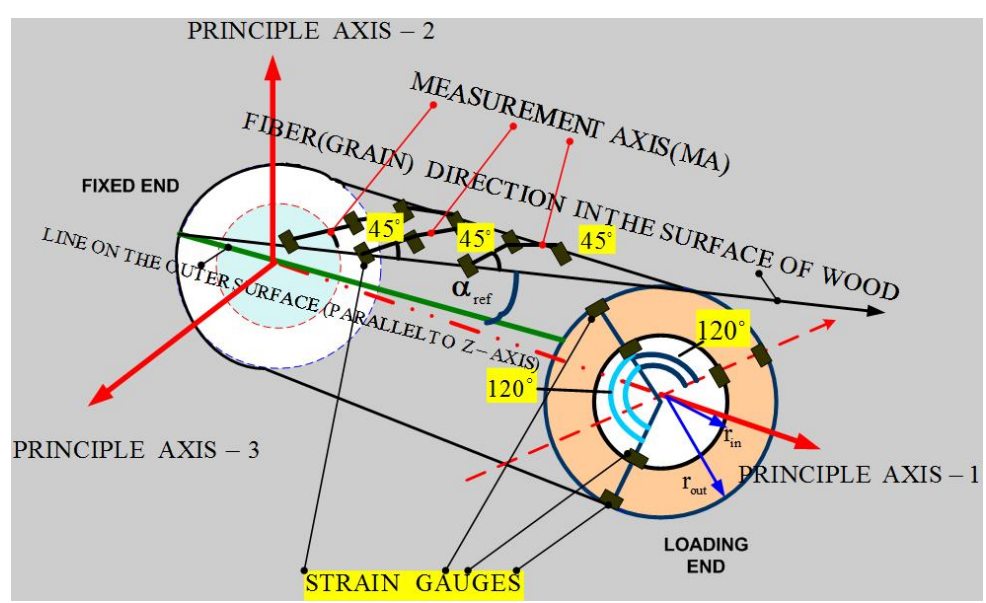

(a)

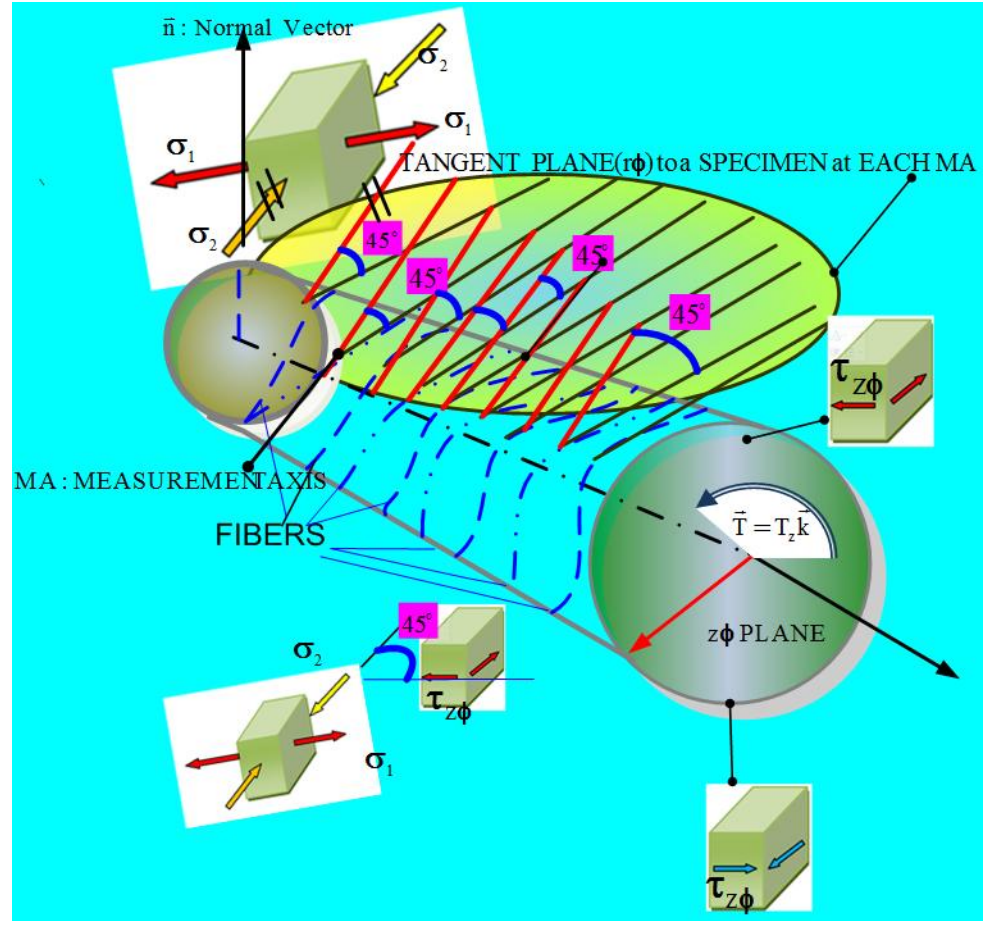

(b)

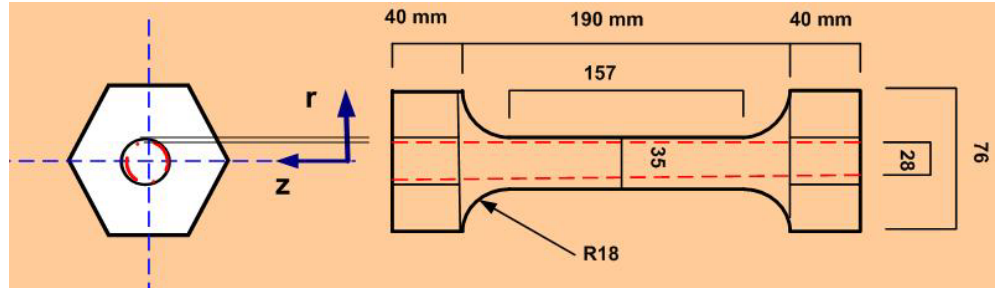

(c)

Figure 1. (a) The specimen was modeled by employing two different coordinate systems. The first coordinate system was the cylindrical coordinate system with $r, \phi, z$ coordinates (global system). The second coordinate system was fiber oriented principal axes system, 1-2-3 or (LRT); (b) MA stands for measurement axis which is taken at $45^{\circ}$ from fiber direction on the tangent plane; (c) Dimensions of tubular pinewood specimen (mm). 


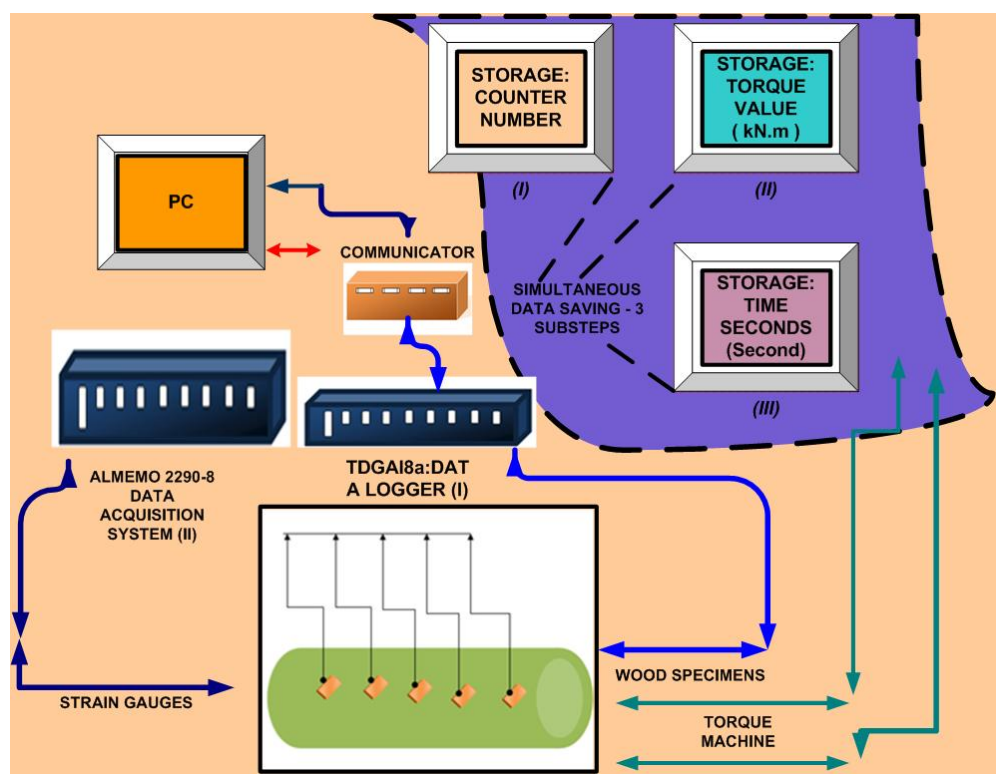

Figure 2. Schematic diagram of the experimental torsion test set-up with data acquisition systems, cables, tubular specimen with gauges on it. Additionally, sequence of the experimental operations were also shown.

Secondly, the variations of point-wise shear modulus values of each specimen were shown as shear modulii $G_{z \phi}(r), G_{z \phi}(\phi), G_{z \phi}(z)$ versus $r, \phi, z$ directions [28]. Subscripts of shear modulus, $z-\phi$ represent the transverse surface; on which the torque was applied, On the other hand, circumferential surface is represented by using subscripts $r-\phi$. Strain gauges, on which measurements were taken, were installed along the $z$-axis (Figure 1(a)). At the following step of the experiment; exponential and quadratic equations of the variations were tabulated. Measurements were performed by considering two reference coordinate systems in order to explain the wood specimen behavior: global cylindrical coordinate system $(r, \phi, z)$ and local coordinate system (wood fiber arrangement based on principal material directions; 1, 2, 3) (Figure 1(a)). The local and global coordinate systems were used together for the definition of MA (measurement axis). MA served as a variable of wood fiber direction $\left(0^{\circ} \leq \alpha_{\text {ref }} \leq 15^{\circ}\right)$. The angular positions of the strain gauges on the circumferential surface relative to $z$-axis, were aligned with respect to maximum shear stress. The maximum shear stress was the stress formed around MA. These angular positions were denoted as MAA (Measurement Axis Angle) and they were taken as Equation (2).

$$
\mathrm{MAA}=\alpha_{\text {ref }}+45^{\circ}
$$

(Each MA lies on the 1-3 principal plane which corresponds to $r-\phi$ plane (Figure 1(b)). Measurement Axis Angle MAA is relatively different from the geometrical central axis angle $\phi$. MAA was defined on the 1-3 principal material plane which was attached on the surface of the cylinder. The first strain gauge was attached with $+45^{\circ}$ angle in the principal material axis-1. All other gauges were also located along this direction (Figure 1(a)). Application of gauges in $r_{\text {in }}, r_{\text {out }}, \phi_{\text {in }}, \phi_{\text {out }}$ locations were repeated in similar way. In the rest of the study, $z$-axis was rotated to be $z^{\prime}$ such that it coincided with MA.

Invariants $I_{1}, I_{2}, I_{3}$ remain constant with respect to coordinate transformations. Stress and strain components were uncoupled along the principal directions for $\theta_{p_{1}}=0^{\circ}$ and $\theta_{p_{2}}=45^{\circ}$ (Figure 1(b)). Only along the principal directions, principal stress and strain values of the isotropic materials coincided with the principal values of fiber composite materials on the Mohr's circle [30] [37] [38]. Thus, it became easier to understand the behavior of the wood material under torsion and to compare it with that of the isotropic material. Accordingly, the shear modulus functions were derived along the MA directions for the corresponding principal stresses and strains. In literature, the shear modulus, shear strength, and principal strain angle were measured from the shear stress/ shear strain relation obtained by Iosipescu shear tests. Tests were conducted, and the validity of the in-plane shear tests was examined for the thin strips of western hemlock (Tsuga Heterophylla Sarg.) [39]. In this 
work, the torque value $T$ as measured incrementally from the torsion testing machine. Variation of $\left(\tau_{z \phi}-\gamma_{z \phi}\right)_{p w}$ were plotted by using the inner or outer shear stresses $\tau_{z \phi}$ and their corresponding principal shear strains. Consequently, shear modulus functions for the principal shear strains and corresponding shear stresses were expressed in terms of $r, \phi, z$ as in Equation (3):

$$
\begin{aligned}
& G_{z \phi}\left(r\left(\mathrm{MA}=\alpha_{\text {ref }} \pm 45^{\circ}\right)\right) \\
& G_{z \phi}\left(\phi\left(\mathrm{MA}=\alpha_{\text {ref }} \pm 45^{\circ}\right)\right) \\
& G_{z \phi}\left(z\left(\mathrm{MA}=\alpha_{\text {ref }} \pm 45^{\circ}\right)\right)
\end{aligned}
$$

Experimental results were discussed in the following section in detail.

\section{Results and Discussion}

Distributions of shear modulus functions and related empirical formulas were determined for pinewood. Beside this, average and equivalent mechanical properties of shear modulus values $G_{\text {avg }}$ corresponding to the average shear stresses $\tau_{z \phi}$ for different types of wood (pine, oak, chestnut, hornbeam) were measured and results were listed in Table 1 . These measurements were performed without using strain gauges and the related data was obtained from the second form of the nonlinear exact tri-linear curve $\left(\tau_{z \phi}-\gamma_{z \phi}\right)$.

In the application direction of torsion loading; since the resultant curves $\left(\tau_{z \phi}-\gamma_{z \phi}\right)$ were affected, different failure values were formed. Applied loading directions $+\alpha_{\text {ref }}$ or $-\alpha_{\text {ref }}$, represent the backward and forward loadings of torque, respectively. Forward loading applications yield higher failure values than the backward ones. The empirical equations of $G_{z \phi}(\phi), G_{z \phi}(z)$ and $G_{z \phi}(r)$ were expressed in terms of various functions and were listed in the Table 2. The descriptions of the results were explained according to the relative differences of slopes in shear stress-strain $\left(\tau_{z \phi}-\gamma_{z \phi}\right)_{p w}$ and their corresponding $G_{z \phi}(r), G_{z \phi}(\phi), G_{z \phi}(z)$ versus $r, \phi, z$ curves for forward loading applications. Figure 3 presents $G_{z \phi}(\phi)$ (GPa) versus $\phi$ (degree) distribution of data obtained from six gauges at $\phi=0^{\circ} / 120^{\circ} / 240^{\circ}$ for the tubular specimen. This distribution is obtained through the specified coordinates of MAA at the outer and/or inner surfaces of specimens (see Figures 1(a)-(c)).

In Figure 3, the outer and inner surface $G_{z \phi}(\phi)$ reactions due to the shear stress-strain distributions were formed in reverse orders at the measurement point where $Z$ is equal to $200 \mathrm{~mm}$. Through the circumferential direction, $G_{z \phi}(\phi)$ forms a convex curve at the inner surface and $G_{z \phi}(\phi)$ forms a concave curve at the outer surface. Figure 4 presents $G_{z \phi}(z)(\mathrm{GPa})$ versus $Z(\mathrm{~mm})$ distribution from four gauges at $z=65,157,177,200 \mathrm{~mm}$ for the tubular specimen. Variation of function $G_{z \phi}(z)$ shows parabolic distribution. It is concluded that $G_{z \phi}(z)$ at the loaded end is bigger than $G_{z \phi}(z)$ at the fixed end. Figure 5 presents

\begin{tabular}{|c|c|c|c|c|c|}
\hline $\begin{array}{l}\text { Material types of } \\
\text { wood specimens }\end{array}$ & $G_{\text {avg }}$ & $\begin{array}{l}\text { Shear modulus (GPa) } \\
\text { (test\#1/test\#2/test\#3/test\#4) }\end{array}$ & $\begin{array}{l}\text { Forward (+) and backward (-) torque } \\
\text { directions (test\#1/test\#2/test\#3/test\#4) }\end{array}$ & $\begin{array}{l}\text { Average shear modulus } \\
\text { values }(\mathrm{GPa}) G_{\text {avg }}\end{array}$ & $\begin{array}{c}\text { Standard } \\
\text { deviation } S_{Y}\end{array}$ \\
\hline Pine (tube) & & $0.29 / 0.46 / 0.27 / 0.32$ & $-/-/+/+$ & 0.34 & 0.085 \\
\hline Pine (solid) & & $0.35 / 0.46 / 0.27 / 0.32$ & $-/-/+/+$ & 0.35 & 0.080 \\
\hline Hornbeam (tube) & & $0.46 / 0.46 / 0.40$ & $+/+/+$ & 0.44 & 0.035 \\
\hline Hornbeam (solid) & & $0.38 / 0.43 / 0.39$ & $+/+/+$ & 0.40 & 0.026 \\
\hline Oak (tube) & & $0.32 / 0.36 / 0.40 / 0.43$ & $+/+/+/+$ & 0.38 & 0.048 \\
\hline Oak (solid) & & $0.47 / 0.43 / 0.3$ & $+/+/+$ & 0.40 & 0.089 \\
\hline Chestnut (tube) & & $0.45 / 0.47 / 0.41$ & $+/+/+$ & 0.44 & 0.031 \\
\hline Chestnut (solid) & & $0.31 / 0.31 / 0.36$ & $+/+/+$ & 0.33 & 0.029 \\
\hline
\end{tabular}
$G_{z \phi}(r)$ (GPa) versus $r(\mathrm{~mm})$ distribution at $\phi=0^{\circ} / 120^{\circ} / 240^{\circ}$ for the data obtained from six gauges at $z=200 \mathrm{~mm}$. It demonstrates dependency of $G_{z \phi}(r)$ (GPa) versus $r(\mathrm{~mm})$ on the MA angles $\phi$. In these 
Table 2. Experimentally determined linear and nonlinear shear modulus functions of pinewood.

\begin{tabular}{|c|c|c|c|c|c|c|}
\hline \multirow{2}{*}{$\begin{array}{c}\text { Fiber angle } \\
\text { (MAA) }\end{array}$} & \multicolumn{3}{|c|}{ Quadratic expressions (Pa) } & \multicolumn{3}{|c|}{ Exponential expressions (Pa) } \\
\hline & $G_{z \phi}(r)$ & $G_{z \phi}(\phi)$ & $G_{z \phi}(z)$ & $G_{z \phi}(r)$ & $G_{z \phi}(\phi)$ & $G_{z \phi}(z)$ \\
\hline GROUPS & \multicolumn{3}{|c|}{ Linear function $G_{z \varphi}(r)=A_{\text {avg }} r+B_{\text {avg }}$} & \multicolumn{3}{|c|}{ Exponential function $G_{z \varphi}(r)=A_{\text {avg }} \mathrm{e}^{B_{\text {avg }} r}$} \\
\hline $\begin{array}{c}45^{\circ} \\
\text { (inner/outer) }\end{array}$ & $\begin{array}{l}G=-4 \times 10^{8} r \\
+8 \times 10^{9}\end{array}$ & & & $G=3 \times 10^{11} \mathrm{e}$ & & \\
\hline $\begin{array}{c}45^{\circ} \\
\text { (outer) }\end{array}$ & & & $\begin{array}{l}G=-4.3 \times 10^{3} z^{2} \\
+4 \times 10^{6} z+4 \times 10^{7}\end{array}$ & & & $G=2 \times 10^{8} \mathrm{e}^{0.0062 z}$ \\
\hline $\begin{array}{c}45^{\circ} \\
\text { (outer) }\end{array}$ & & $\begin{array}{l}G=9.9 \times 10^{4} \phi^{2} \\
-2 \times 10^{7} \phi+8 \times 10^{9}\end{array}$ & & & $7 \times 10^{9} \mathrm{e}$ & \\
\hline $\begin{array}{c}45^{\circ} \\
\text { (inner/outer) }\end{array}$ & $\begin{array}{l}G=-2 \times 10^{10} r \\
+3 \times 10^{11}\end{array}$ & & & $G=8 \times 10^{14} \mathrm{e}$ & & \\
\hline $\begin{array}{c}45^{\circ} \\
\text { (outer) }\end{array}$ & & $\begin{array}{l}G=-4.3 \times 10^{3} z^{2} \\
+4 \times 10^{6} z+4 \times 10^{7}\end{array}$ & & & & $G=2 \times 10^{8} \mathrm{e}^{0.0062 z}$ \\
\hline $\begin{array}{c}45^{\circ} \\
\text { (inner) }\end{array}$ & & $\begin{array}{l}G=-2 \times 10^{6} \phi^{2} \\
-3 \times 10^{8} \phi+6 \times 10^{10}\end{array}$ & & & $8 \times 10^{10} \mathrm{e}$ & \\
\hline $\begin{array}{c}45^{\circ} \\
\text { (inner) }\end{array}$ & & $\begin{array}{l}G=-3 \times 10^{3} \phi^{2} \\
+6.7 \times 10^{5} \phi+3 \times 10^{8}\end{array}$ & & & $3 \times 10^{8} \mathrm{e}^{-}$ & \\
\hline $\begin{array}{c}45^{\circ} \\
\text { (inner/outer) }\end{array}$ & $\begin{array}{l}G=-5 \times 10^{8} r \\
+9 \times 10^{9}\end{array}$ & & & & $3 \times 10^{11} \mathrm{e}$ & \\
\hline $\begin{array}{c}45^{\circ} \\
\text { (outer) }\end{array}$ & & $\begin{array}{l}G=-2.37 \times 10^{4} \phi^{2} \\
+6 \times 10^{6} \phi+7 \times 10^{8}\end{array}$ & & & $8 \times 10^{8} \mathrm{e}^{-}$ & \\
\hline $\begin{array}{c}45^{\circ} \\
\text { (outer) }\end{array}$ & & & $\begin{array}{l}G=-5.9 \times 10^{4} z^{2} \\
-1 \times 10^{7} z+5 \times 10^{9}\end{array}$ & & & $G=4 \times 10^{8} \mathrm{e}^{0.0036 z}$ \\
\hline
\end{tabular}

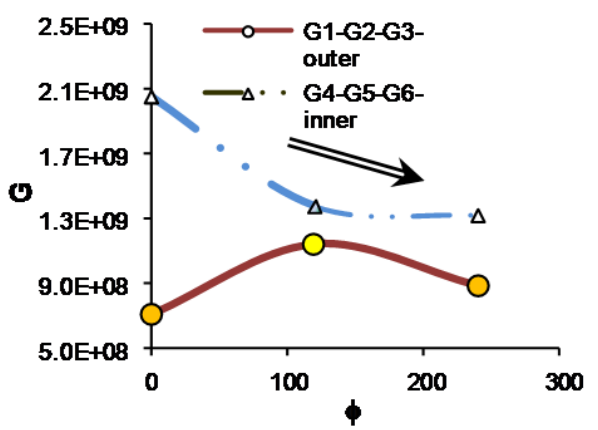

Figure 3. Plots of $G_{z \phi}(\phi)$ (GPa) versus $\phi \quad$ (degree) at $z=200 \mathrm{~mm}$.

tests, gauges were located on both inner and outer surfaces with $\phi=0^{\circ}, 120^{\circ}, 240^{\circ}$ (see Figure 6). At these locations of $\phi$, the variations of $G_{z \phi}(r)$ from inner to outer surface decrease. Hence, it is concluded that:

1) $G_{z \phi}(r)(\mathrm{GPa})$ versus $r(\mathrm{~mm})$ varies linearly along the circumferential surface. This is a consequence of $G_{z \phi}(r)$ values on the inner surface are being bigger than $G_{z \phi}(r)$ values on the outer surface.

2) Shear stresses formed on the outer surface are smaller than the shear stresses formed on the inner surface because shear stresses on the inner surface accumulate densely and shear stresses on the outer surface do not accumulate that densely. 


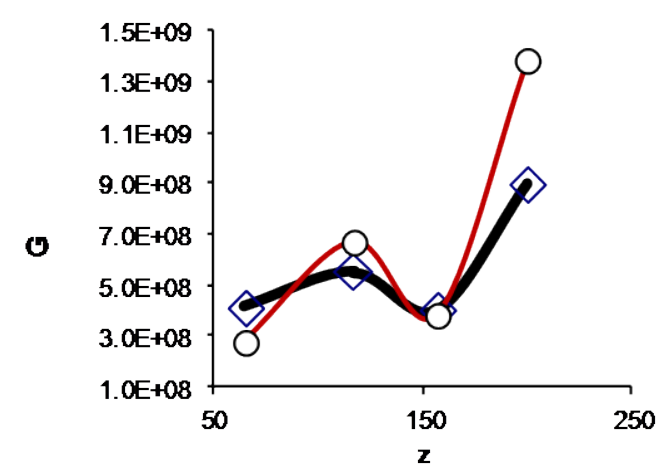

Figure 4. Two plots of $G_{z \phi}(z)$ (GPa) versus $z$ (mm) at $z=65,157,177,200 \mathrm{~mm}$.

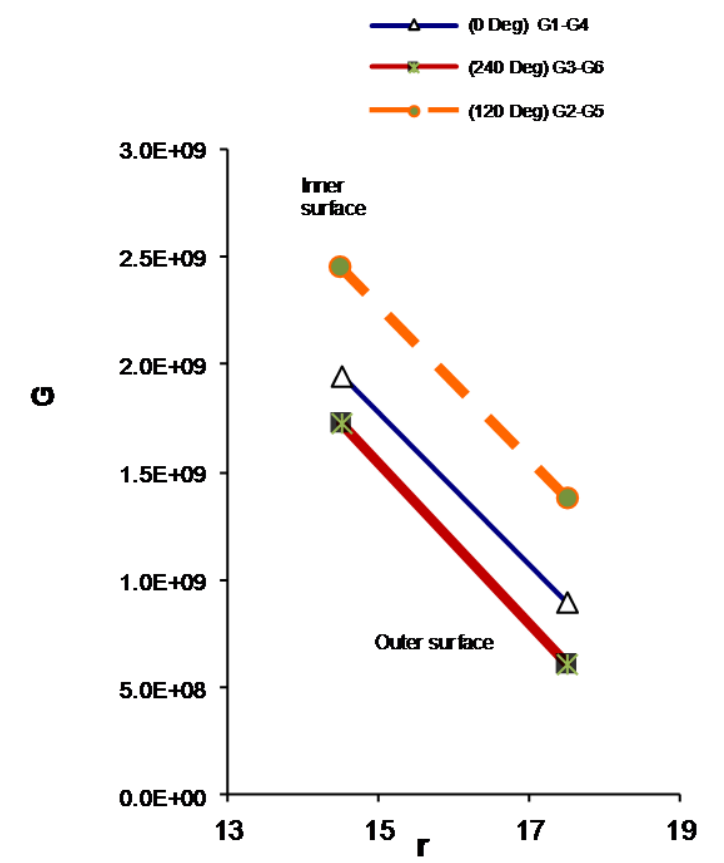

Figure 5. Plots of $G_{z \phi}(r)(\mathrm{GPa})$ versus $r(\mathrm{~mm})$ at $z=200 \mathrm{~mm}$.

Empirical expressions of $G_{z \phi}(\phi), G_{z \phi}(z)$ and $G_{z \phi}(r)$ were obtained for tubular specimens by statistically evaluating the coefficients $A_{\text {avg }}, B_{\text {avg }}, C_{\text {avg }}$ from the related experimental data. These coefficients were tabulated in Table 3 in five groups (GPa) with their standard deviation $\left(\mathrm{S}_{\mathrm{Y}}\right)$, coefficient of deviation (c.v.) and mean values (GPa) as follows:

1) First group coefficients of the linear and exponential $G_{z \varphi}(r)$ functions were $A_{\text {avg }}=-0.24, B_{\text {avg }}=5.1$ and $A_{\text {avg }}=22.4, B_{\text {avg }}=-0.13$ respectively. 2) Second group coefficients of the parabolic and exponential $G_{z \varphi}(\varphi)$ functions were obtained as $A_{\text {avg }}=-2.35 \times 10^{4}, B_{\text {avg }}=1.76 \times 10^{6}, C_{\text {avg }}=6.2 \times 10^{8}$ and $A_{\text {avg }}=1.19$, $B_{\text {avg }}=4.0 \times 10^{-4}$ respectively. 3) Third group coefficients of the parabolic functions $G_{z \varphi}(\varphi)$ on the inner surface of the tubular specimens were $A_{\text {avg }}=-3.78 \times 10^{4}, B_{\text {avg }}=2.65 \times 10^{6}, C_{\text {avg }}=6.875 \times 10^{8}$. Corresponding coefficients for the exponential function were calculated as $A_{\text {avg }}=10.13, B_{\text {avg }}=1.75 \times 10^{-4}$. 4) Fourth group coefficients of the parabolic functions $G_{z \varphi}(\varphi)$ on the outer surface were $A_{\text {avg }}=0.72 \times 10^{4}, B_{\text {avg }}=0.74 \times 10^{6}$, $C_{\text {avg }}=5.43 \times 10^{8}$. Coefficients for the exponential function were obtained as $A_{\text {avg }}=13.75, B_{\text {avg }}=6.13 \times 10^{-4}$, accordingly. 5) Fifth group coefficients of the parabolic functions $G_{z \varphi}(z)$ on the outer surface were obtained as $A_{\text {avg }}=-0.5 \times 10^{4}, B_{\text {avg }}=-3.65 \times 10^{6}$ and $C_{\text {avg }}=14.3 \times 10^{8}$. Corresponding coefficients for the exponential function were determined as $A_{\text {avg }}=0.21, B_{\text {avg }}=7.5 \times 10^{-3}$ (Table 2). 


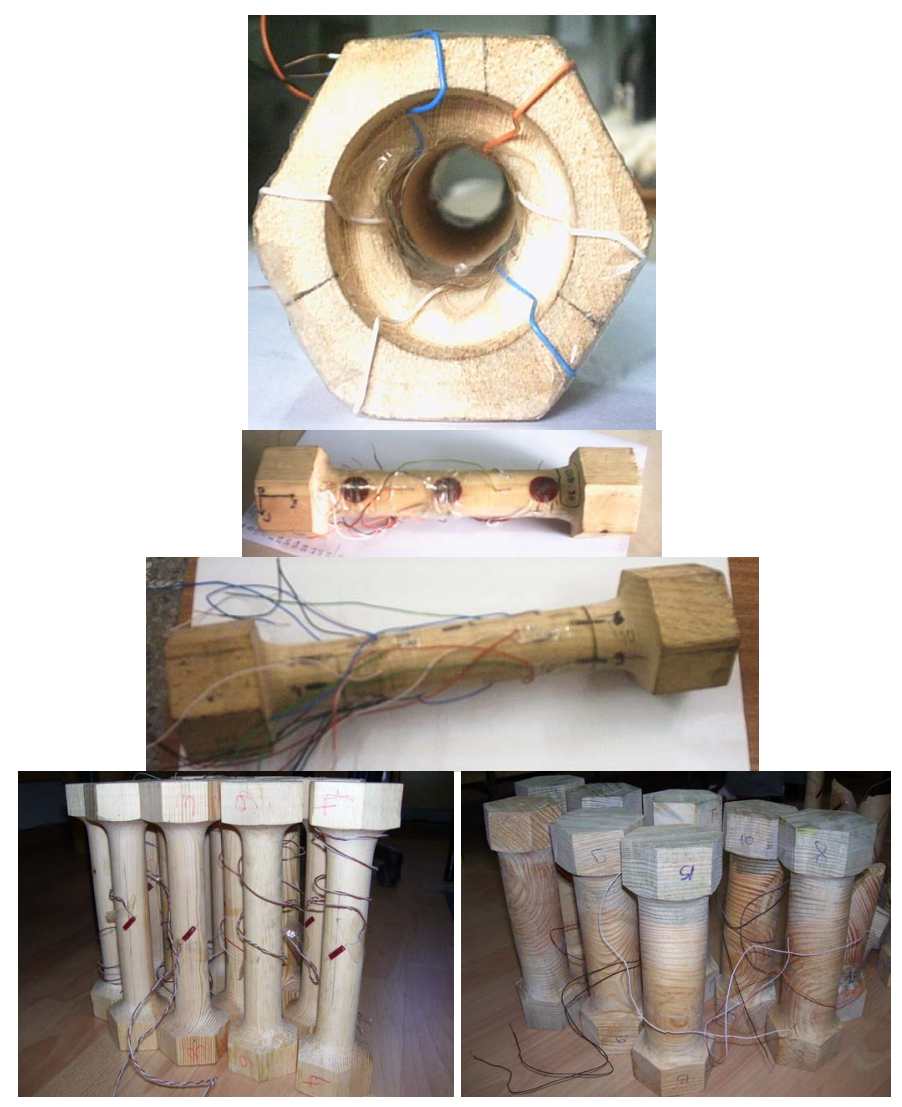

Figure 6. Pinewood specimens with strain gauges.

\section{Conclusions}

In this research study, variations of the shear modulus of transversely isotropic pinewood specimens under torsion were examined. The set of equations of shear modulus in $z-\phi$ and $r-\phi$ planes along the principal directions were formulated. All measurements were performed in terms of local coordinate system. As a continuation of this study for the future an extended experimental study is planned. In this future study it is suggested to calculate additional shear modulus functions and related coefficients by using different loading types on different wood species. As is known, the elastic constants' matrix $C_{i j}$ appearing in the Hooke's general law is used to define the elastic constants of materials. In this matrix, it is possible to identify these constants in the form of linear and nonlinear functions by replacing $G_{z \phi}(r), G_{z \phi}(\phi)$ and $G_{z \phi}(z)$ with $G_{13}, G_{23}$ and $G_{21}$ for the pinewood (Pinus sylvestris L.) material.

Results were summarized below as follows:

1) In our study, we have shown that $\tau_{z \phi}$ and $\tau_{r \phi}$ can be written as $\tau_{z \phi}(r, \phi, z)$ and $\tau_{r \phi}(r, \phi, z)$ and these functional values can be calculated by substituting the values of the normal strain components $\varepsilon_{r}, \varepsilon_{\phi}, \varepsilon_{z}$ and the shear strain terms $\gamma_{r \phi}, \gamma_{z \phi}, \gamma_{r z}$ into the Hooke's general law (Equation (4)). The equations obtained by replacing linear and nonlinear shear modulus functions with unknown elastic constants, can be used in theoretical and numerical researches [28].

$$
\begin{aligned}
& \tau_{\phi z}=C_{14} \varepsilon_{r}+C_{24} \varepsilon_{\phi}+C_{34} \varepsilon_{z}+C_{44} \gamma_{\phi z}+C_{45} \gamma_{r z}+C_{46} \gamma_{r \phi} \\
& \tau_{r \phi}=C_{16} \varepsilon_{r}+C_{26} \varepsilon_{\phi}+C_{36} \varepsilon_{z}+C_{46} \gamma_{\phi z}+C_{56} \gamma_{r z}+C_{66} \gamma_{r \phi}
\end{aligned}
$$

2) According to our study it is concluded that, $G_{z \phi}(z)$ values at $z$ is equal to $200 \mathrm{~mm}$ are greater than the $G_{z \phi}(z)$ values at $z$ is equal to $70 \mathrm{~mm}$. Similarly, $G_{z \phi}(\phi)_{\text {outer }}$ values are smaller than the $G_{z \phi}(\phi)_{\text {inner }}$ values, and, $G_{z \phi}(r)$ values at $\mathrm{z}$ is equal to $200 \mathrm{~mm}$ are larger than $G_{z \phi}(r)$ values at $\mathrm{z}$ is equal to $70 \mathrm{~mm}$.

3 ) In our study it is also defined that, obtained shear modulus values along the $0^{\circ}$ fibers are larger than the other two $45^{\circ}$ and $90^{\circ}$ directed measurements performed with tri-axial rosette gauges. Results obtained from 
Table 3. Shear modulus linear/nonlinear functions including the statistical values of the coefficients (GPa).

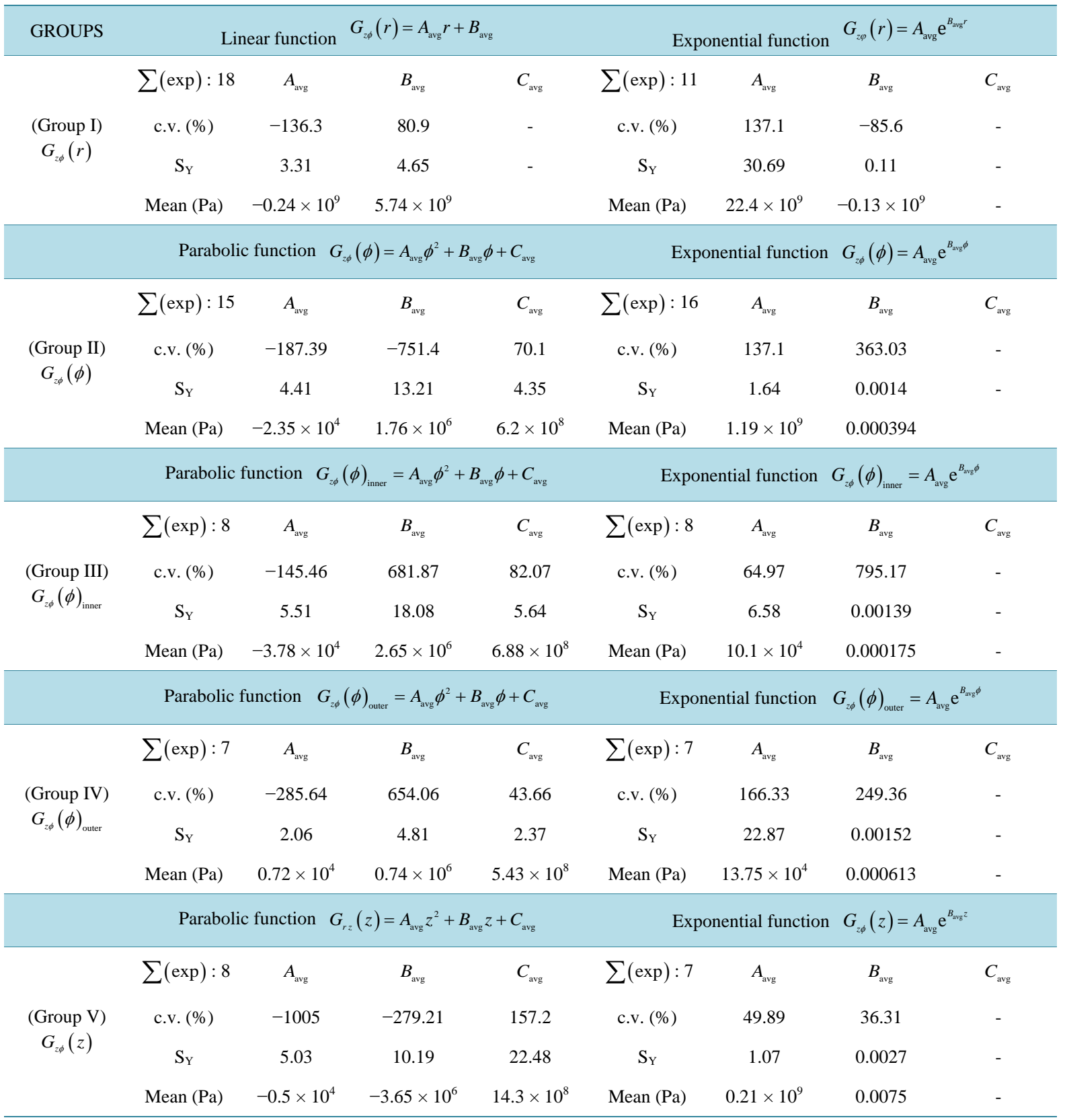

measurements along the $0^{\circ}$ oriented wood fibers, yield very small positive or negative shear strain values in general. Additionally, forward or backward loadings cause extension or contraction along the fibers and in turn, this generates positive or negative shear strains respectively.

4) The negative shear strains which develop at the measurement points as a consequence of forward loading applying can be explained by contraction of the material along the fibers. Thus, behavior of the shear strains are dependent both upon arrangement of the wood fibers and the load applying direction (Table 3).

5) According to the results of measurements along the MA directions using tri-axial rosette gauges, we have concluded that, the relative shear strain changes between $0^{\circ}-45^{\circ}$ and $45^{\circ}-90^{\circ}$ angles are not equal to each other. The difference of shear strains between the $0^{\circ}-45^{\circ}$ directions is smaller than the directions between $45^{\circ}-90^{\circ}$.

We recommend further additional experiments, in order to enhance the understanding of complex wood behavior under torsion loading. The stress accumulation phenomenon at the critical points along the wood fibers 
should be supported by further experimental studies in future and in our opinion this is especially important for the aircraft engineering area.

\section{Acknowledgements}

The authors would like to thank the Gazi University for financial support (BAP) (Grant Ref No: 6/2003-21).

\section{References}

[1] Wooster, W.A. (1949) A Textbook on Crystal Physics. Cambridge University Press, London.

[2] Bozorth, R.M. (1951) Ferromagnetism. Van Nostrand, New York.

[3] Turley, J. and Sines, G. (1971) The Anisotropy of Young's Modulus Shear Modulus and Poisson's Ratio in Cubic Materials. Journal of Physics D: Applied Physics, 4, 264-271. http://dx.doi.org/10.1088/0022-3727/4/2/312

[4] Saliklis, E.P. and Falk, R.H. (2000) Correlating Off-Axis Tension Tests to Shear Modulus of Wood-Based Panels. Journal of Structural Engineering, 126, 621-625. http://dx.doi.org/10.1061/(ASCE)0733-9445(2000)126:5(621)

[5] Salmén, L. (2004) Micromechanical Understanding of the Cell-Wall Structure. CR Biologies, 327, 873-880. http://dx.doi.org/10.1016/j.crvi.2004.03.010

[6] Yoshihara, H. and Ohta, M. (1992) Stress-Strain Relationship of Wood in the Plastic Region. I. Examination of the Applicability of Plasticity Theories. Mokuzai Gakkaishi, 38, 759-763.

[7] Yoshihara, H. and Ohta, M. (1994) Stress-Strain Relationship of Wood in the Plastic Region. II. Formulation of the Equivalent Stress-Equivalent Plastic Strain Relationship. Mokuzai Gakkaishi, 40, 263-267.

[8] Yoshihara, H. and Ohta, M. (1995) Determination of the Shear Stress-Shear Strain Relationship of Wood by Torsion Tests. Mokuzai Gakkaishi, 41, 988-993.

[9] Yoshihara, H. and Ohta, M. (1997) Analysis of the Shear Stress/Shear Strain Relationships in Wood Obtained by Torsion Tests. Mokuzai Gakkaishi, 43, 457-463.

[10] Ramberg, W. and Osgood, W.R. (1943) Description of the Stress-Strain Curves by Three Parameters. National Advisory Committee for Aeronautics. US Government Printing Office, Washington DC, Tech. Note No. 902.

[11] O’Halloran, M.R. (1973) Curvilinear Stress-Strain Relationship for Wood in Compression. Ph.D. Dissertation, Colorado State University, Fort Collins.

[12] Foschi, R.O. (1974) Load-Slip Characteristics of Nails. Wood Science, 17, 69-77.

[13] Hu, J. (1990) Strength Analysis of Wood Single Bolted Joints. Ph.D. Thesis, University of Wisconsin, Madison.

[14] Werner, H. (1993) Bearing Capacity of Dowel-Type Wood Connections Accounting for the Influence of Relevant Parameters. Ph.D. Dissertation, Karlsruhe University, Karlsruhe.

[15] Davalos-Sotelo, R. and Pellicane, P.J. (1992) Bolted Connections in Wood under Bending/Tension Loading. Journal of Structural Engineering, 118, 999-1013. http://dx.doi.org/10.1061/(ASCE)0733-9445(1992)118:4(999)

[16] Patton-Mallory, M., Cramer, S.M., Smith, F.W. and Pellicane, P.J. (1997) Nonlinear Material Models for Analysis of Bolted Wood Connections. Journal of Structural Engineering, 123, 1063-1070. http://dx.doi.org/10.1061/(ASCE)0733-9445(1997)123:8(1063)

[17] Patton-Mallory, M., Smith, F.W. and Pellicane, P.J. (1998) Modeling Bolted Connections in Wood: A Three-Dimensional Finite-Element Approach. Journal of Testing and Evaluation, 26, 115-124. http://dx.doi.org/10.1520/JTE11981J

[18] Yoshihara, H., Ohsaki, H., Kubojima, Y. and Ohta, M. (1999) Applicability of the Iosipescu Shear Test on the Measurement of the Shear Properties of Wood. Journal of Wood Science, 45, 24-29. http://dx.doi.org/10.1007/BF00579520

[19] Ayina, O. and Morlier, P. (1998) Modelling the Behavior of Wood under a Constant Torque. Materials and Structures/Materiaux et Constructions, 31, 405-410.

[20] Tabiei, A. and Wu, J. (2000) Three-Dimensional Nonlinear Orthotropic Finite Element Material Model for Wood Composite Structures. Composite Structures, 50, 143-149. http://dx.doi.org/10.1016/S0263-8223(00)00089-1

[21] Magorou, L.L., Bos, F. and Rouger, F. (2002) Identification of Constitutive Laws for Wood-Based Panels by Means of an Inverse Method. Composites Science and Technology, 62, 591-596. http://dx.doi.org/10.1016/S0266-3538(01)00149-X

[22] Francescato, P., Pastor, J. and Enab, T. (2005) Torsional Behavior of a Wood-Based Composite Beam. Journal of Composite Materials, 39, 865-879. http://dx.doi.org/10.1177/0021998305048731

[23] Dahl, K.B. and Malo, K.A. (2009) Nonlinear Shear Properties of Spruce Softwood: Numerical Analyses of Experimental Results. Composites Science and Technology, 69, 2144-2151. 
http://dx.doi.org/10.1016/j.compscitech.2009.05.011

[24] Dahl, K.B. and Malo, K.A. (2009) Linear Shear Properties of Spruce Softwood. Wood Science and Technology, 43, 499-525. http://dx.doi.org/10.1007/s00226-009-0246-5

[25] Dahl, K.B. and Malo, K.A. (2009) Nonlinear Shear Properties of Spruce Softwood: Experimental Results. Wood Science and Technology, 43, 539-558. http://dx.doi.org/10.1007/s00226-009-0247-4

[26] Liu, J.Y. and Ross, R.J. (2005) Relationship between Radial Compressive Modulus of Elasticity and Shear Modulus of Wood. Wood and Fiber Science, 37, 201-206.

[27] Gunay, E. and Konakl1, S. (2004) The New Formed Shear Modulus Formulations for the Transversely Isotropic Fiber Composite Bars under Torsion Loading. Journal of the Faculty of Engineering and Architecture of Gazi University, 19, $1-12$.

[28] Gunay, E. and Konakl1, S. (2006) Formation of Shear Stress Equations for Transversely Isotropic Finite Length Bar under Torsion. Science and Engineering of Composite Materials, 13, 255-270. http://dx.doi.org/10.1515/SECM.2006.13.4.255

[29] Uludogan, E. (2005) Coordinate Dependent Experimental Determination of Shear Modulus for Transversely Isotropic Composites by using Wood Torsion Specimens. MSc. Thesis, Gazi University, Institute of Science and Technology, Ankara.

[30] Gunay, E. and Uludogan, E. (2007) Experimental Determination of Shear Modulii Variation of Typical Transversely Isotropic Wood Specimens. Journal of Machine Design and Manufacturing, 9, 67-87.

[31] TQSM21 (1982) Torsion Testing Machine Manual. TecQuipment Ltd., Nottingham.

[32] http://www.tecquipment.com

[33] Almemo (2003) Datalogger Unit Manual V5: Ahlborn Mess- und Regelungstechnik GmbH. Medewitzer, Straße14, 02633 Gaussig, Berlin.

[34] http://www.ahlborn.com

[35] Inan, M. (1970) Strength of Materials. Ofset Printing Ltd. Company, Istanbul.

[36] Gunay, E. and Orçan, Y. (2007) Experimental Investigation of the Mechanical Behavior of Solid and Tubular Wood Species under Torsional Loading. Turkish Journal of Engineering and Environmental Sciences, 31, 89-118.

[37] Gunay, E., Aygun, C. and Uludogan, E. (2012) Empirical Formulation of Shear Modulus Functions for Tubular Pinewood Specimens. 11th International Conference on Sustainable Energy Technologies (Set-2012), SET-2012-348, Vancouver, 2-5 September 2012, 1152-1162.

[38] Gibson, R.F. (1994) Principles of Composite Material Mechanics. McGraw-Hill Inc., Singapore City.

[39] Yoshihara, H. and Matsumoto, A. (2005) Measurement of the Shearing Properties of Wood by In-Plane Shear Test Using a Thin Specimen. Wood Science and Technology, 39, 141-152. http://dx.doi.org/10.1007/s00226-004-0283-z 
Scientific Research Publishing (SCIRP) is one of the largest Open Access journal publishers. It is currently publishing more than 200 open access, online, peer-reviewed journals covering a wide range of academic disciplines. SCIRP serves the worldwide academic communities and contributes to the progress and application of science with its publication.

Other selected journals from SCIRP are listed as below. Submit your manuscript to us via either submit@scirp.org or Online Submission Portal.
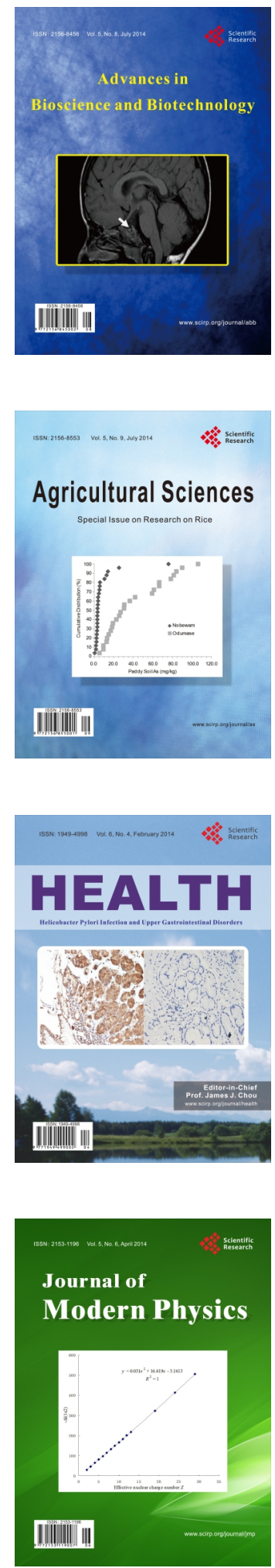
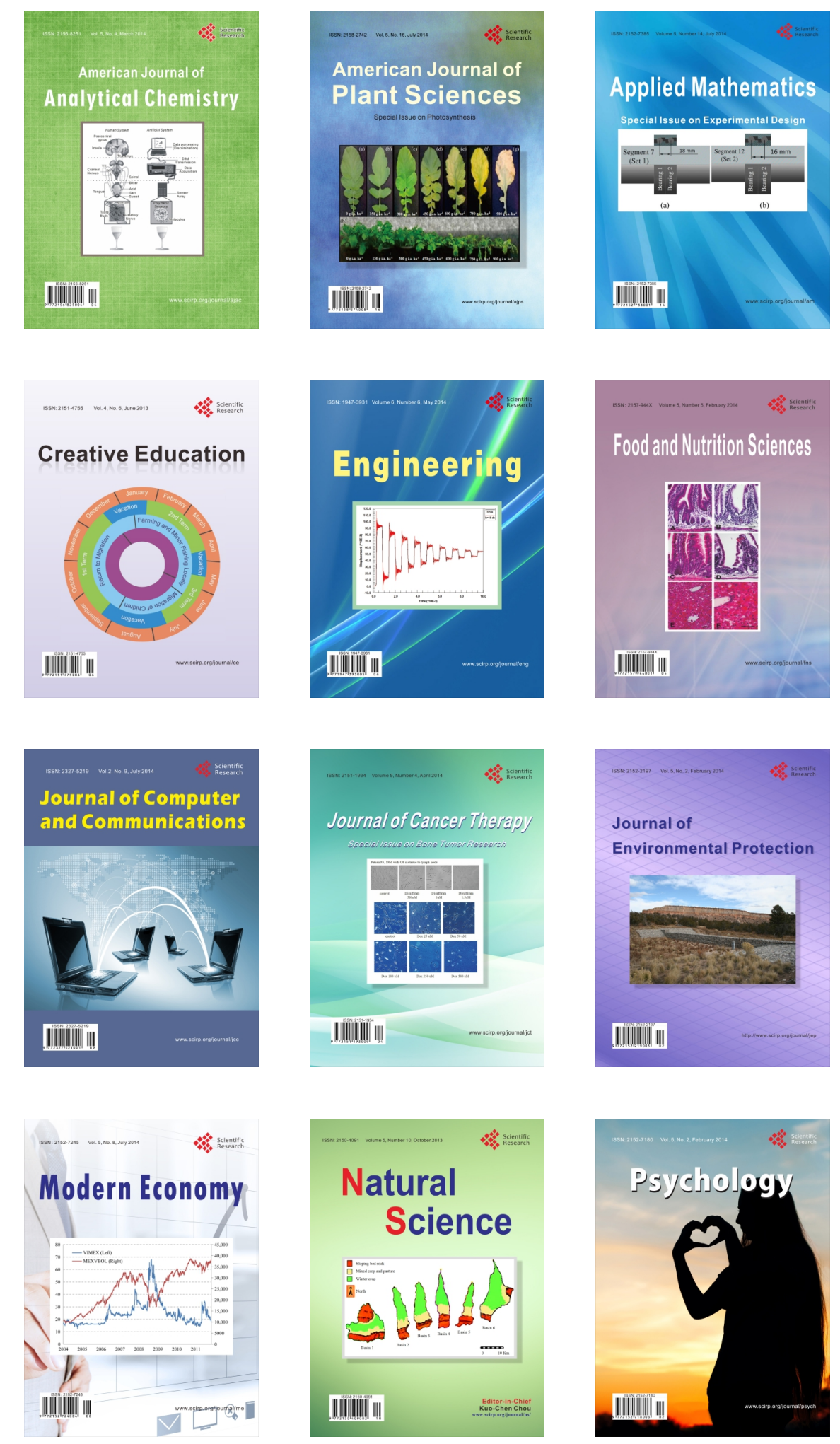